DOSSIÊ TEMÁTICO: A medicalização da educação no Brasil e no Chile: diferentes perspectivas

dol https://doi.org/10.22481/praxisedu.v15i36.5864

\title{
O DIAGNÓSTICO DE TDAH NA PERSPECTIVA DE ESTUDANTES COM QUEIXA ESCOLAR
}

ADHD DIAGNOSIS FROM THE PERSPECTIVE OF STUDENTS WITH SCHOOL COMPLAINTS

\section{DIAGNÓSTICO DE TDAH DESDE LA PERSPECTIVA DE ESTUDIANTES CON QUEJA ESCOLAR}

Maria Izabel Souza Ribeiro

Faculdade de Educação da Universidade Federal da Bahia - Brasil

Lygia de Sousa Viégas

Faculdade de Educação da Universidade Federal da Bahia - Brasil

Elaine Cristina de Oliveira

Instituto de Ciências da Saúde da Universidade Federal da Bahia - Brasil

\begin{abstract}
Resumo: O presente artigo objetiva discutir o diagnóstico de Transtorno de Déficit de Atenção e Hiperatividade (TDAH) a partir da perspectiva de crianças e adolescentes com queixa escolar. Inicialmente, delineia como o TDAH comparece no Manual de Diagnóstico e Estatísticas dos Transtornos Mentais, definição criticada por seu caráter medicalizante, desvelado à luz da abordagem Histórico-Cultural. Em seguida, apresenta o método adotado no trabalho de campo, para então apresentar e analisar, à luz do referencial histórico-crítico, as falas de seis crianças e adolescentes sobre o principal critério para diagnóstico de TDAH. Espera-se, com a discussão proposta, contribuir com a leitura crítica dos problemas de comportamento no contexto escolar.
\end{abstract}

Palavras chave: Abordagem histórico-cultural. Medicalização. TDAH.

\begin{abstract}
This article discusses the diagnosis of Attention Deficit Hyperactivity Disorder (ADHD) from the perspective of children and adolescents with school complaints. Initially, it outlines the description of ADHD in The Diagnostic and Statistical Manual of Mental Disorders, a classification that is criticized for its medicalizing characteristic from a Historical-Cultural approach. Next, the methods adopted in the fieldwork are described, and, lastly, the statements of six children and adolescents about the main criterion for the diagnosis of ADHD are presented, along with an analysis of these statements in the light of a historical-critical approach. The goal of the discussion is to contribute to a critical interpretation of behavior problems in the school context.
\end{abstract}

Keywords: ADHD. Medicalization. Historical-cultural approach. 
Resumen: Este artículo tiene como objetivo discutir el diagnóstico del transtorno de déficit de atención con hiperactividad (TDAH) desde la perspectiva de niños y adolescentes con quejas escolares. Inicialmente, describe cómo aparece el TDAH en el Manual de Diagnóstico y Estadísticas de Trastornos Mentales, una definición criticada por su carácter medicalizante, revelada bajo un enfoque históricocultural. Luego, presenta el método adoptado en el trabajo de campo, para a continuación presentar y analizar, basado en el marco histórico-crítico, las declaraciones de seis niños y adolescentes sobre el criterio principal para el diagnóstico de TDAH. Se espera, con la discusión propuesta, contribuir a la lectura crítica de los problemas de conducta en el contexto escolar.

Palabras-clave: TDAH. Medicalización. Enfoque historico-cultural.

\section{Introdução}

O presente artigo objetiva discutir o diagnóstico de Transtorno de Déficit de Atenção e Hiperatividade (TDAH) a partir da perspectiva de crianças e adolescentes encaminhados para um serviço de psicopedagogia com queixas relativas ao comportamento hiperativo ou desatento $^{1}$. Tais encaminhamentos foram desencadeados pela escola, caracterizando a queixa escolar (SOUZA, 2007). Como sustentáculo da queixa, a suposição de que problemas vivenciados no processo de escolarização podem ser consequência de transtornos mentais que precisam ser diagnosticados e tratados. Dentre esses transtornos, o TDAH é um dos mais referenciados nas escolas (MOYSÉS; COLLARES, 2010), de onde se destaca a relevância desta pesquisa.

Inicialmente, apresentamos como o TDAH comparece no Manual de Diagnóstico e Estatísticas dos Transtornos Mentais (DSM-5, 2014), perspectiva tensionada por meio da crítica aos processos de medicalização da educação (Fórum sobre Medicalização da Educação e da Sociedade [FÓRUM], 2019). Nessa crítica, destacamos a complexidade envolvida no comportamento de prestar atenção às atividades escolares, à luz da abordagem HistóricoCultural de Vigotski² $(1995,1997,2003)$.

Em seguida, apresentamos o método da pesquisa, para então trazer as falas das crianças e adolescentes participantes, as quais serão analisadas à luz dos referenciais teóricos anunciados. Finalizando, são tecidas considerações, na expectativa de contribuir para a compreensão da complexidade do comportamento de estudantes no contexto escolar.

\footnotetext{
${ }^{1}$ Trata-se de recorte de uma Tese de Doutorado (RIBEIRO, 2015).

${ }^{2}$ Para grafia do nome de Vigotski adotaremos a transliteração utilizada por Zoia Prestes, tradutora de obras do autor. Para mais informações, ver sua Tese de Doutorado que apresenta uma análise de obras de Lev Semionovitch Vigotski traduzidas no Brasil e demonstra equívocos na tradução de alguns conceitos (2010).
} 


\section{Compreendendo o TDAH em uma perspectiva crítica}

"Vivemos a Era dos Transtornos”, como denunciam Moysés e Collares (2014, p. 21). Essa afirmação categórica se materializa no chão escolar, onde nomes de transtornos mentais às vezes são mais referenciados que teorias pedagógicas. Dentre os tantos transtornos popularizados, destaca-se o TDAH, por ser um dos mais mencionados.

A legitimação do TDAH no campo da saúde mental tem uma história controversa (MOYSÉS; COLLARES, 2010). Contudo, a partir da 5a edição do Manual de Diagnóstico e Estatística dos Transtornos Mentais (DSM-5, 2014), o TDAH passa a ser classificado como “transtorno do neurodesenvolvimento", caracterizado por um "padrão persistente de desatenção e/ou hiperatividade-impulsividade que interfere com o funcionamento ou desenvolvimento" (DSM-5, 2014, p. 69) $)^{3}$.

Longe de consensual, essa definição tem sido alvo de críticas, sobretudo pelo processo de medicalização envolvido na sua construção. Sendo medicalização um conceito polissêmico (OLIVEIRA; HARAYAMA; VIÉGAS, 2016), cumpre explicitar a definição aqui adotada:

[...] medicalização envolve uma racionalidade que naturaliza a vida humana, e, no mesmo giro reducionista e determinista, formata quais são os tipos "naturalmente" valorizados ou desvalorizados, desejáveis ou indesejáveis. Sua penetração na vida cotidiana se dá a partir de diversos dispositivos estratégicos e práticos, instalados em todos os espaços e instituições (escolas, postos de saúde, igrejas, templos, banheiros, ônibus, ruas, mídias...), que operam em torno de matrizes normativas e ideais regulatórios, prescrevendo padrões (de desenvolvimento, comportamento, aprendizagem, inteligência, afetividade, linguagem, gênero, sexualidade, eficiência, estética...) que devem ser seguidos à risca por todos, invisibilizando a complexidade da existência e camuflando o fato de que as condições de vida são absurdamente desiguais. (FÓRUM, 2019, p. 12).

Assim, o olhar medicalizante "desconsidera a complexidade da vida humana, reduzindo-a a questões de cunho individual, seja em seu aspecto orgânico, seja em seu aspecto psíquico, seja em uma leitura restrita e naturalizada dos aspectos sociais” (FÓRUM, 2015a).

A literatura científica acumula publicações que desvelam as polêmicas em torno da classificação, definição, diagnóstico e tratamento do TDAH, a partir de diversas áreas de atuação (medicina, pedagogia, farmácia, psicologia), bem como de abordagens teóricas. Sem a

\footnotetext{
${ }^{3}$ Boa parte das características do TDAH presentes no DSM-5 são as mesmas definidas no DSM-IV. As principais mudanças foram no sentido de incluir exemplos com adultos, alterar a idade de referência, permitir diagnósticos em comorbidade com o transtorno do espectro autista e delimitar o número de sintomas para o diagnóstico de adolescentes. Todas essas alterações, essencialmente, ampliam o campo de alcance do diagnóstico (SOUZA, 2015).
} 
intenção de esgotar essa diversidade, e sem condições de aprofundar cada uma, referenciamos os trabalhos de Lima (2005), Moysés e Collares (2010, 2014), Brzozowski e Caponi (2012).

Nos valemos da abordagem histórico-cultural de Vigotski para tecer críticas à medicalização presente no diagnóstico do TDAH, na medida em que esse suposto transtorno reflete uma naturalização do comportamento e da atenção. Segundo Vigotski, em que pese a importância da estrutura biológica, ela é apenas o ponto de partida para o desenvolvimento das funções psíquicas superiores, sendo o contexto histórico-cultural "o fator mais importante que determina e organiza o comportamento humano" (VIGOTSKI, 2003, p. 40). Ainda em suas palavras, as funções psíquicas superiores: "surgen en el proceso del desarrollo social del niño por medio de la traslación a sí mesmo de las formas de colaboración que el niño asimila durante la interacción con el medio social que lo rodea."4 (VIGOTSKI, 1997, p. 219). Assim, rompendo com uma leitura determinista, naturalizante e biologizada, Vigotski (1995) compreende que o cérebro humano é o cérebro de um ser social.

No caso específico da atenção, o autor afirma que "la atención voluntaria, tanto por su composición, como por su estructura y función, no es el simple resultado del desarrollo natural, orgánico de la atención, sino el resultado de su cambio y reestructuración por la influencia de estímulos-medios externos"5 (VIGOTSKI, 1995, p. 224). Nesse processo, inicialmente, assume papel fundamental a orientação dos adultos (com destaque para os professores), em meio às atividades sociais (com destaque para as escolares). Se é certo que também a escolha individual afeta o domínio da atenção, mesmo essa vontade resulta do desenvolvimento cultural, não sendo determinada biologicamente.

Nesse sentido, na classificação do TDAH, a atenção voluntária, função psicológica superior resultante do desenvolvimento sócio-histórico, é confundida com a atenção involuntária, função psicológica elementar determinada biologicamente, desconsiderando a complexa relação entre os planos cultural e biológico, bem como o processo de enraizamento do sujeito na cultura. À luz da abordagem histórico-cultural de Vigotski, compreende-se que a (des)atenção em atividades escolares possui relação direta com o processo de escolarização. No entanto, pela ótica do DSM, só se focaliza o comportamento infanto-juvenil, fora do contexto, supondo a existência de um "nível de desenvolvimento normal" que remete à padronização naturalizada do humano.

\footnotetext{
4 “surgem no processo de desenvolvimento social da criança através da transferência para si mesmo das formas de colaboração que a criança assimila durante a interação com o meio social que a rodeia" (tradução nossa).

5 "A atenção voluntária, tanto por sua composição como por sua estrutura e função, não é o simples resultado do desenvolvimento natural, orgânico da atenção, mas o resultado de sua mudança e reestruturação devido à influência dos estímulos-meio externos" (tradução nossa).
} 
Chama a atenção que, ao mesmo tempo em que o DSM afirma taxativamente que o TDAH é determinado biologicamente, desde a quarta edição ele reconhece que "Nenhum exame laboratorial ou avaliação neurológica ou da atenção foi estabelecido como diagnóstico na avaliação clínica do Transtorno de Déficit de Atenção/Hiperatividade” (DSM-IV, 2003, p. 115). Tal fragilidade não é superada na quinta edição (DSM-5, 2014), que reitera: “os sintomas são difíceis de distinguir de comportamentos normativos altamente variáveis antes dos 4 anos de idade" (p. 72); "podem também existir variações culturais nas atitudes para com ou na interpretação dos comportamentos das crianças"; e "as avaliações de sintomas informativos podem ser influenciadas pelo grupo cultural da criança e do informador" (p. 73).

O fato é que esse suposto transtorno neurológico não possui teste neurológico capaz de detectá-lo. Ao contrário, o diagnóstico é feito, sobretudo, a partir da aplicação de um questionário fechado, o SNAP-IV, o qual será explorado mais adiante. Mas desde logo é possível afirmar que, à revelia da complexidade envolvida no comportamento infanto-juvenil, e desse comportamento no contexto escolar, confirma-se um diagnóstico de um suposto transtorno orgânico com base em um questionário atravessado pela cultura.

De posse de um diagnóstico biologizante, inicia-se o tratamento, geralmente a administração de um medicamento tarja preta, o cloridrato de metilfenidato (princípio ativo da Ritalina ${ }^{\circledR}$, Ritalina LA® e Concerta $\left.{ }^{\circledR}\right)$. Curiosamente, também a bula (NOVARTIS, 2010) afirma que "não há teste diagnóstico específico" para o TDAH (p. 1). E sobre seus efeitos, declara que "O mecanismo pelo qual ele exerce seus efeitos psíquicos e comportamentais em crianças não está claramente estabelecido, nem há evidência conclusiva que demonstre como esses efeitos se relacionam com a condição do sistema nervoso central" (p. 5).

Desconsiderando tantos alertas, esse psicoestimulante tem sido prescrito como dispositivo de controle de estudantes com queixa escolar. É o que denuncia a Nota Técnica $O$ consumo de Psicofármacos no Brasil, publicada pelo Fórum sobre Medicalização da Educação e da Sociedade (2015b). Nela, são apresentados dados da dispensação de alguns psicofármacos, dentre os quais o Cloridrato de Metilfenidato, em unidades particulares registradas pelo Sistema Nacional de Gerenciamento de Produtos Controlados (SNGPC) da Agência Nacional de Vigilância Sanitária (ANVISA), entre outubro de 2007 e setembro de 2014. Segundo a Nota Técnica, a importação de Ritalina no Brasil aumentou em 300\% entre 2012 e 2013, atingindo $1.820 \mathrm{~kg}$. É notável, ainda, que seu consumo acompanha o calendário escolar.

Tal fenômeno reflete a patologização e a medicamentalização, facetas perversas da lógica medicalizante: expressões e experiências humanas traduzidas em supostos transtornos ou doenças que devem ser tratados com fármacos cujos efeitos não são assegurados. O próprio 
SNGPC, no Boletim de Farmacoepidemiologia (2012), denuncia que "O uso do medicamento metilfenidato tem sido muito difundido nos últimos anos de forma, inclusive, equivocada, sendo utilizado como 'droga da obediência' e como instrumento de melhoria do desempenho seja de crianças, adolescentes ou adultos” (p. 13). Tal situação é preocupante, já que esse fármaco pode "ocasionar dependência física, psíquica e/ou outro tipo de risco conhecido ou em potencial para a saúde humana em uma população" (p. 13).

Nesse cenário, torna-se urgente desvelar a complexidade do comportamento infantil, rompendo com a perspectiva medicalizante. Essa tarefa foi assumida na presente pesquisa, que propôs uma inversão na lógica dominante e priorizou ouvir o que estudantes de quem se suspeita que sejam portadores do suposto TDAH têm a dizer sobre esse diagnóstico. O que pensam sobre seus comportamentos e os contextos nos quais eles se dão? Eles são sintomas de um transtorno neurológico ou devemos considerar a dinâmica de funcionamento da vida social e escolar?

\section{Método}

Buscando superar a análise reducionista da desatenção e hiperatividade infanto-juvenil na escola, em 2013 foi realizada pesquisa qualitativa a fim de conhecer a perspectiva de estudantes sobre o suposto TDAH. A escolha metodológica por ouvi-los inspira-se em Patto (1990) e Checchia (2006), na medida em que, classicamente, eles têm sido os "grandes ausentes" nas pesquisas educacionais, que tendem a priorizar o discurso sobre eles, em contraposição a suas falas.

Como primeiro passo, foi realizado um levantamento de todas as Fichas Cadastrais preenchidas e arquivadas em um Núcleo de Psicopedagogia situado em uma instituição de ensino superior privada na cidade do Salvador-BA para onde estudantes com queixa escolar são encaminhados. O levantamento, que incluiu os casos em atendimento e a lista de espera, do início do ano de 2012 até outubro de 2013, tinha por objetivo identificar a queixa que motivou o encaminhamento, a idade, a série e o turno de frequência na escola. Ele também permitiu selecionar seis estudantes para participarem da pesquisa, à luz dos seguintes critérios: estarem na faixa etária entre 11 e 13 anos de idade, aguardando na lista de espera, com queixas escolares que remetem aos critérios diagnósticos do TDAH: agitado, inquieto, desconcentração, impaciência, dispersa, déficit de atenção.

Para garantir o sigilo, seus nomes foram substituídos por outros escolhidos por eles: Messi, menino de 11 anos, no $4^{\circ}$ ano Ensino Fundamental (EF); Goku, menino de 11 anos, no $2^{\circ}$ ano EF; Bombeiros SD Gomes 612, menino de 12 anos, no $3^{\circ}$ ano EF; Malu!!!, menina de 
12 anos, no $5^{\circ}$ ano EF; Bombom, menino de 12 anos, no $6^{\circ}$ ano EF; e Zeus deus dos oceanos, menino de 13 anos, no $6^{\circ}$ ano EF. Entre os participantes, havia quem possuía diagnóstico de TDAH assinado por especialistas da área da saúde e quem estava em busca de avaliação para confirmar o diagnóstico. Para três deles, houve prescrição de cloridrato de metilfenidato.

Os encontros foram realizados no contraturno escolar, com periodicidade semanal e duração de uma hora e meia, totalizando 14 encontros, nos quais foram realizadas atividades dialógicas, jogos e situações que requisitavam atenção, memória, percepção, pensamento e criatividade, dentre outros processos cognitivos. As atividades também exigiam compreensão e respeito, tanto às regras das propostas, quanto ao convívio com outros participantes. Era intenção do grupo oportunizar que todos compartilhassem concepções, percepções e sentidos atribuídos a si próprios, aos outros, ao contexto escolar e às suas histórias.

No artigo, apresentamos a análise de um encontro no qual os participantes conheceram e responderam o SNAP-IV. Trata-se de um questionário construído a partir do DSM-IV, que tem servido como principal critério para diagnóstico do TDAH. Ele é composto por 18 perguntas, sendo as nove primeiras sobre desatenção e as nove últimas, hiperatividade e impulsividade. Geralmente, pais e professores são convidados a preencher o questionário sobre seus filhos e alunos, marcando objetivamente uma das quatro opções de resposta: Nem um pouco, Só um pouco, Bastante e Demais (ABDA, 2017).

Nesse sentido, o diagnóstico é construído a partir da percepção de adultos, sem que seja possível qualificar a situação concreta em que os comportamentos se dão. Na presente pesquisa, ao contrário, rompendo a frieza dos protocolos, estudantes com queixa escolar, diagnosticados ou candidatos ao rótulo, foram convidados a contextualizar suas condutas, a partir de suas vivências. Primeiro, ouçamos o que eles dizem. Em seguida, serão tecidas considerações à luz dos referenciais teóricos que fundamentam esta pesquisa.

\section{O que crianças e adolescentes com queixa escolar têm a dizer sobre o SNAP-IV?}

$\mathrm{Na}$ tessitura da pesquisa, os participantes conheceram o SNAP-IV, sendo convidados a pensar os critérios para o diagnóstico à luz da experiência concreta. Assim, cada uma das 18 perguntas do questionário foi literalmente reproduzida (e aqui é apresentada em negrito), e, uma a uma, respondida pelos estudantes, que, quando confirmaram que se comportam daquela forma, trouxeram situações da vida em que tais "sintomas" aconteceram.

Ao primeiro sintoma, Não consegue prestar muita atenção a detalhes ou comete erros por descuido nos trabalhos da escola ou tarefas, eles responderam: 
Messi: Os trabalhos da escola nunca cometi erro não, mas o dever às vezes cometo erro. No dever minha mãe ensina, depois vou lá na escola, está errado, aí falo "mãe está errado", aí ela pega "deixe eu ver", ela vê, depois apaga tudo, manda eu fazer mais uma vez. Por causa que às vezes eu não sei fazer o dever direito.

Goku: Não cometo erro não. Um pouco. Quando está na sala tem vezes que apronto, tem vezes que apronto na sala.

Bombeiros: Sim, demais. Que eu não fico perto no quadro.

Malu: Só um pouco. Sempre no texto a gente tem que ter um pouco de cuidado na hora de fazer os parágrafos certos, essas coisas, ponto de interrogação, às vezes eu esqueço de colocar, a professora vai lá e corta e tira meu ponto, aí pronto.

Bombom: Muito não, só um pouco. Quando a professora passa o dever eu não consigo prestar muita atenção. Eu tiro minha atenção com o lápis, brincando.

Zeus: Bastante. Nas atividades da escola e também nos trabalhos. [Por quê?] Rapaz na verdade não sei. Às vezes, quando quero prestar atenção, aí presto. Quando não gosto também, da matéria...

Assim, todos, em alguma medida, dizem distrair-se ou cometer erros nas atividades escolares. Os motivos relatados, no entanto, não parecem determinados biologicamente, mas marcados pelo contexto educacional: não saber fazer determinada lição, não gostar da matéria, confundir-se e mesmo se deixar levar por alguma distração durante a explicação na aula.

\section{O segundo sintoma, Tem dificuldade de manter a atenção em tarefas ou atividades}

de lazer, mobilizou a todos, que apontaram diferenças entre escola e lazer:

Messi: Tenho só um pouco porque às vezes os meninos ficam pedindo um bocado de coisa, aí não presto atenção na aula, pedem lapiseira, lápis, caneta, aí toda hora tem que parar pra dar. [E nas atividades de lazer?] Eu presto atenção. [Quando presta atenção?] Quando eu fico quieto aí ninguém me pede nada aí eu pego presto atenção mesmo. Eu fico ligado na professora, depois eu bebo água, e fico com ela até ela acabar. [Você acompanha a professora?] Quando a professora está falando demais eu penso em jogar bola, brincar de pega-pega, e... só isso. [Quando não pensa em outras coisas?] Quando ela fala menos e faz dever, depois acaba e manda a gente responder.

Goku: Um pouco. Dos negócios lá, das tarefas, eu faço educação física, faço tudo. [Quais não presta atenção?] As difíceis. [E atividades de lazer, brincadeira?] Presto bastante.

Bombeiros: Só um pouco. [Quais tarefas?] De tarefa, né, matemática. [E nos jogos?] Consigo. [Qual é a diferença?] Porque os meninos ficam bagunçando.

Malu: É que nas atividades de lazer a gente fica mais à vontade, aí, sei lá, na maioria das atividades que eu faço eu não presto muito atenção, que eu estou em casa mesmo, na hora da atividade de lazer eu não presto muito atenção, 
pego ali na geladeira uma coisa, num sei que... Quando a gente está comendo a gente está focando mais na comida, não está focando no texto, no trabalho, aí pronto. [Na brincadeira?] Consigo.

Bombom: Nas tarefas só um pouco. [E nas atividades de lazer?] Não. [Qual é a diferença?] Porque uns são mais fáceis e outros são difíceis. [O que é mais fácil?] A professora passar um desenho e o difícil é ela passar um texto, alguma coisa de ler.

Zeus: Não. Nem um pouco. [Por quê?] Rapaz, não sei, é porque não tem muita gente, muitas pessoas, aí eu presto atenção; é porque eu quero mesmo. [Qual é a diferença?] A diferença na verdade é porque eu quero e também por causa que não tem muita gente, porque com muita gente aí eu não presto atenção muito.

As respostas indicam que suas distrações se articulam à dificuldade da tarefa proposta, bem como à presença de colegas, que desperta a vontade de brincar e trocar entre si. Interessante destacar o estranhamento de Malu à pergunta, já que ela entende o lazer como espaço de relaxamento, sem grandes exigências de atenção.

O terceiro sintoma, Parece não estar ouvindo quando se fala diretamente com ele, foi negado por Goku e Bombeiros. Ouçamos os outros:

Messi: quando minha mãe me chama eu falo "espera aí rapidinho, que vou assistir aqui, depois eu vou", ela pega: "venha logo", aí eu vou, e às vezes quando meu irmão me chama quando estou assistindo o jogo do Barcelona não atendo não, fico lá no sofá ateeé acabar o jogo, depois eu vou. [E na escola?] Quando jogo bola os meninos fica me chamando pra eu ser do time, aí não fico escutando, aí falo pros meninos "por que você não me chamou, velho?", "ah, você não ouviu, parece que é surdo", "eu estava conversando", aí a gente vai pra sala.

Malu: Oxe! Cansa de acontecer isso, minha mãe fala até que é pirraça. [Quais momentos?] Quando estou focada no computador, Ave Maria!, na televisão e quando estou no celular.

Bombom: Só um pouco. Quando eu estou brincando de bola, aí alguém fica me chamando, chamando, chamando.

Zeus: Demais. Quando estou assistindo televisão e quando estou no computador.

As respostas acima seriam tidas como sintoma de desatenção. No entanto, a partir das situações, notamos que a desatenção ao chamado de alguém geralmente se dá porque estão atentos a outras coisas, como a televisão, o computador, o celular, ou o futebol.

Sobre o quarto sintoma, Não segue instruções até o fim e não termina deveres de escola, tarefas ou obrigações, eis suas respostas: 
Messi: Eu consigo até o fim, só paro pra beber água, aí depois volto e faço mais uma vez. Quando a professora faz uma atividade ela espera a gente acabar pra fazer outra, e depois mais outra, e depois do recreio, volta 4 horas, faz outra e mais outra até $4 \mathrm{~h} 30$.

Goku: Sigo. Tem vezes que eu deixo. Tem vezes que é bastante, tem vezes que é pouco. [Quando não vai até o fim?] Quando não sei, acontece um pouco.

Bombeiros: Deixo pela metade só um pouco. É que a aula termina cedo e não dá tempo.

Malu: Oh! Quando tenho um dever pra fazer que as respostas eu sei, eu respondo, agora as que não sei, deixo pra fazer na escola, que na escola a professora vai me explicar melhor, então eu deixo pelo meio. Só se eu não souber, é só um pouco.

Bombom: Às vezes não faço tudo. [Por quê?] O horário do reforço acaba, quando chego em casa, chego cansado e não faço. Quando chego da escola, vou logo para o reforço.

Zeus: Nada, eu gosto de fazer tarefas, de fazer dever, assim, agora só quando eu não consigo mesmo fazer, que está difícil mesmo é que eu deixo em branco.

Nota-se, portanto, que todos mostram empenho em realizar as tarefas, mas por vezes não a fazem até o fim pelo volume de tarefas ou por terem dúvidas e dificuldades. Pelos seus relatos, notamos que são todas situações cotidianas nas escolas e que, portanto, poderiam ser sanadas a partir do trabalho pedagógico.

$\mathrm{O}$ quinto sintoma, Tem dificuldade para organizar tarefas e atividades, foi negado por Bombeiros e Bombom. Já Malu se disse desorganizada "em todas as tarefas". Os outros participantes citaram situações que remetem ao cotidiano escolar e a seus interesses pessoais:

Messi: Porque... cada matéria, aí eu falo "pró, que matéria é hoje?", ela fala "português", aí boto na página de português, ou "matemática", boto na página de matemática, aí depois vou mudando, mudando; o que a gente faz mais lá é português e matemática. [E a dificuldade?] Porque a professora manda a gente fazer uma, depois manda terminar pra depois fazer a de matemática; quando foi a primeira vez, a professora mandou fazer o dever aí já acabou a matéria de português, tive que botar em outra matéria, só que não tava tão organizado assim. [O que provoca essa dificuldade?] A professora passa muito dever.

Goku: Tenho, muito. É porque não sei ler direito, não sei ler não. [Quem ajuda a organizar as tarefas?] Meus colegas lá.

Zeus: Algumas vezes, são poucas. Quando estou com pressa, quando tenho alguma coisa, pra ligar o computador logo, aí às vezes eu ligo primeiro o computador e deixo ligado pra eu já estar na consciência que o computador está ligado, aí quando eu terminar lá a coisa que estou fazendo, aí vou pro computador, o computador já está ligado. 
Novamente, as dificuldades para organizar as tarefas relatadas remetem ao processo de escolarização: eles falam de sobrecarga de matérias e tarefas, e Goku declara que não sabe ler direito, sendo ajudado por colegas, e não pela professora.

Para o sexto sintoma, Evita, não gosta ou se envolve contra a vontade em tarefas que exigem esforço mental prolongado, Bombeiros disse que mesmo não gostando, faz e evita “só um pouco". Zeus tenta fazer. Já Bombom, quando "é muito trabalho", às vezes não quer fazer. Eis o que disseram os outros participantes:

Messi: Eu faço [a cópia do quadro] até o fim, depois não respondo, aí a pró manda responder, aí eu falo "espera aê, professora, deixa eu descansar", aí quando descanso bem, bem, bem, que bebo água, vou no banheiro, aí respondo. Quando a pró passa muito dever eu paro e fico na cadeira esperando, esperando, esperando, depois faço, fico fazendo. [Quais deveres ou atividades exigem muito?] Os assuntos da prova, porque a professora passa muito dever, aí ela manda a gente estudar, estudar, estudar, estudar, depois quando a gente chega pra fazer a prova não tem nada que a gente estudou. Ninguém gosta de muito dever, não. Coisa cansativa é ficar escrevendo, prestando atenção, escrevendo, escrevendo, até terminar pra aprender a escrever direito, fazer a letra melhor, aprender a ler e prestar muita atenção.

Goku: Eu perco minha cabeça, não sei fazer os deveres todos não. [Como é perder a cabeça?] Não saber de nada, oxe, não sei nem fazer o dever direito ainda. [E faz o quê?] Brinco, essas coisas.

Malu: Eu só faço por obrigação. Porque acho que dói muito minha cabeça, puxa muito minha mente, depois que termino de fazer, alguém me chama, eu fico toda agoniada com dor de cabeça, toda estressada de fazer. [Quais?] Matemática e história, essas duas. [E o que você faz?] Tento me esforçar, né, na hora de fazer o dever me esforço, tento fazer, depois quando não consigo eu descanso um pouco, deixo o dever lá, bebo água, assisto televisão quando tiver um pouquinho descansada volto pro dever e faço, aí consigo.

Mais uma vez, o que parece orientar o comportamento das crianças e adolescentes é a experiência escolar, sobretudo quando ainda não dominaram os conteúdos exigidos ou quando há uma sobrecarga de tarefas. Ainda assim, declaram tentar realizá-las.

Quanto ao sétimo sintoma, Perde coisas necessárias para atividades (p. ex: brinquedos, deveres da escola, lápis ou livros), ele foi negado categoricamente por Goku, Bombeiros e Zeus. Messi perdeu "uma caneta só”. Bombom perde "só um pouco", citando lápis, caneta e borracha. Malu foi a única que disse "bastante".

Ao sintoma oito, Distrai-se com estímulos externos, apenas Bombeiros disse que "nada" o distrai. Bombom e Goku se distraem "um pouco", geralmente com algo que chama a atenção. Os outros três participantes disseram se distrair demais ou bastante, relatando situações concretas que roubam a atenção na escola: 
Messi: Quando os meninos passam, da outra sala, que ninguém gosta deles, porque procuram briga; aí a gente fica falando com a professora, a professora vai lá na diretoria, aí a gente fica olhando, olhando, aí a professora manda todo mundo ficar quieto e prestar mais atenção na aula; quando as meninas de lá da minha sala ficam ali no portão perto da diretoria, dançando, aí fico olhando, depois eu "professora, as meninas ali estão dançando", a professora vai e não faz nada ou manda entrar; quando a diretora fica falando com a professora, fico olhando, a professora está falando alguma coisa; quando o vigia fica reclamando, olho pra ver quem é; quando os meninos fica correndo, eu olho, só isso.

Malu: Se eu não tiver focada na explicação da professora até um lápis que passar e cair, eu vejo, até um pássaro que passar... Eu estou aqui, aí se passar um pássaro, eu já vejo; qualquer coisa tira minha atenção, até a pessoa falando, conversando com outro, aí que eu já não foco mais na atividade, foco em outra coisa.

Zeus: Quando está passando uma música que eu goste, na rua, aí atrai minha atenção, ou uma coisa chamativa, sabe? Aí atrai.

O nono sintoma, É esquecido em atividades do dia-a-dia, foi novamente negado por

Goku e Bombeiros. Messi disse que a única coisa que não lembra é de tomar café. Bombom às vezes "esquece" de fazer metade do dever, sobretudo quando tem muito. Malu precisa "estudar bastante" para não esquecer os conteúdos aprendidos na escola. Zeus disse que na escola não esquece, mas em casa esquece bastante:

Quando... estou na televisão, aí minha mãe fala né "oh vou sair, aí faça isso, isso e isso", como aconteceu hoje, aí esqueci, eu disse "tá bom", aí estava motivado na televisão e esqueci. Eu disse "tá", mas como uma resposta, pra ela não ficar pensando que não estou escutando.

\section{Com relação ao décimo sintoma, Mexe com as mãos ou os pés ou se remexe na}

cadeira, apenas Bombeiros negou. Todos os outros disseram se mexer, por variados motivos: Zeus age assim para se distrair. Bombom se mexe mesmo quando está realizando as tarefas. Malu se balança quando fica inquieta ou nervosa, como quando há "Muito barulho, muita pessoa gritando, um bocado de coisa, até se minha mãe gritar comigo”. Ouçamos Messi:

Quando a professora fala alguma coisa, eu fico estalando os dedos, estalando, estalando, ela olha no celular, fica olhando, fala "rapidinho vou ali e volto", liga pra alguém, depois volta e "não sei de nada não, faça seu negócio sozinho".

Sua resposta é simbólica pois, embora a pergunta se refira ao seu comportamento visto de forma isolada, ele relata situações em que a professora se distrai, sai da sala ao longo da aula ou se recusa à tarefa docente. Apesar de todos esses comportamentos serem sintomas de TDAH, 
não nos parece que era sua intenção diagnosticar a professora. Ao contrário, ele parece nos lembrar que os comportamentos na escola não são maquinais, e todos em algum momento agem fora do padrão esperado, até mesmo a professora. Mexer-se na cadeira, quando o turno escolar é de quatro a cinco horas, não parece algo determinado por transtorno neurológico.

Para o sintoma 11, Sai do lugar na sala de aula ou em outras situações em que se espera que fique sentado, Malu disse que, embora tenha vontade, não sai "nem um pouco". Bombom só sai na hora do intervalo, porque se sair durante a aula, "a professora manda para a diretoria”. Bombeiros, Goku e Messi levantam para falar com a professora. Goku também disse que às vezes levanta para brincar, e Messi acrescentou que sai para ir ao banheiro, conversar com a diretora ou pegar e devolver um material emprestado de algum colega. Só Zeus disse que sai demais do lugar, contextualizando:

É difícil explicar. Quando vejo meus colegas, um sai da sala, aí saio também, fico pra lá e pra cá, conversando com um, com outro, não gosto muito de ficar sem fazer nada, sozinho, gosto de conversar. [E na aula?] Também. Na verdade, não pode, né? O professor pensa que estou perturbando, aí não estou, eu levanto pra pedir alguma coisa pro colega, lapiseira, borracha, caneta, essas coisas.

Quanto ao sintoma 12, Corre de um lado para outro ou sobe demais nas coisas em situações em que isto é inapropriado, Malu, Bombom, Messi, Zeus e Bombeiros disseram que não. A fala de Goku recupera o sentido do corpo livre na infância:

Tem vezes que subo na árvore na casa de minha tia. Na escola, não. Eu só fico brincando, subo no negócio pra brincar de carrossel, mas não brinco mais não, eu subia. Tem vez que eu subo, tem vez que é bastante, tem vez que é pouco.

Sobre o sintoma 13, Tem dificuldade em brincar ou envolver-se em atividades de lazer de forma calma, Goku, Bombom e Zeus disseram que não. Bombeiros disse que sim. Malu perspicazmente lembrou que "depende da brincadeira". Perguntamos, então, quais eram as brincadeiras preferidas. Goku gosta de "todas". Bombeiros, de futebol e correr. Messi gosta de jogar bola, e Zeus, de jogos que "envolvem corpo físico". Tanto Messi quanto Zeus citam jogo da velha, abc ou xadrez, mas preferem atividades corporais. Apenas Malu prefere brincadeiras de concentração, como jogos eletrônicos. A brincadeira preferida da maioria, portanto, é inviável de forma calma, o que é sintetizado por Bombom: ele gosta de brincadeiras “de movimento". Zeus afirma que quando brinca, seu corpo fica "alegre e agitado". Messi diz:

eu fico falando: "bora, bora, bora, corre, corre, corre, corre, toca, toca, toca", é que eu movimento muito e fico muito alegre, muito alegre; tem outra brincadeira sem correr também, mas as de correr são mais divertidas, porque 
ajuda você ficar mais forte, ajuda você se alimentar mais, ficar alimentando, alimentando, alimento bom, e brincar parado não dá pra ajudar em nada.

O sintoma 14 é Não para ou frequentemente está a "mil por hora". Bombom e Malu disseram que não. Goku disse não saber, afirmando ora que sim, ora que não. Bombeiros fica "um pouquinho agitado" quando os outros meninos perturbam, e Zeus, alegremente, disse que "é ali que consigo gastar todas as minhas energias, demais". Messi fica "mais calmo" na aula, e contou quando fica "um pouco agitado":

Quando brinco de bola, quando assisto, aí fico "pô velho, você viu o jogo do Barcelona, do Real Madrid", aí, fico falando rapidão, ninguém entende, quando estou um pouco menos é porque sento lá no sofá, ligo a televisão, vou escovar os dentes, às vezes tomo café, fico lá assistindo, depois vou pra escola e volto.

Quanto ao sintoma 15, Fala em excesso, Bombeiros, Bombom e Messi disseram que "só um pouco", sendo que esse último acrescentou: "quando estou em casa fico falando, na escola, tenho que prestar atenção". Já Goku, Zeus e Malu disseram que bastante. Zeus explicou que gosta muito de conversar, e Malu comentou: "Falo, desde pequena, demais; minha mãe me chamava de papagaio".

Sobre o sintoma 16, Responde as perguntas de forma precipitada antes delas terem sido terminadas, Goku e Bombeiros disseram que não. Bombom disse que às vezes e Zeus, demais. Os outros participantes explicaram:

Messi: Eu espero a pessoa terminar, aí penso, penso, penso, aí "ah, já sei a resposta, é essa aí, velho, oh".

Malu: Só em avaliação e teste, por exemplo, quando minha mãe pega o caderno e vai me perguntar alguma coisa que eu sei, aí quando minha mãe ainda está falando, eu falo, respondo, aí ela "está certo".

Quanto ao sintoma 17, Tem dificuldade de esperar sua vez, Malu e Bombeiros disseram esperar, e Bombeiros acrescenta: "porque é falta de educação”. Goku espera, embora por vezes ele diga que "não aguenta mais". As falas de Messi, Bombom e Zeus dão concretude às situações em que é difícil esperar:

Messi: Eu espero minha vez, aí fico esperando, depois fico batendo os pés, aí a professora "espera, já vai chegar, já vai chegar", fico esperando, esperando, aí quando chego, pego e vou pra sala.

Bombom: Quando vai apresentar, sempre me deixa por último, eu quero ser logo o primeiro. 
Zeus: Às vezes eu dou um pouco de adiantamento, quando a gente bate sorteio pra ver quem vai ficar na linha ou quem vai ficar no gol, aí "bora, bora, se adianta logo, bora, bora", mas eu espero.

\section{Por fim, o sintoma 18, Interrompe os outros ou se intromete (p.ex. mete-se nas} conversas/jogos), Bombeiros e Malu disseram que não. Messi especificou que só interrompe a irmã. Já Bombom e Zeus disseram que interrompem "só um pouco". Apenas Goku qualificou: "Tem vez que me meto nas conversas de adulto; bastante".

A presente seção priorizou as falas de Messi, Goku, Bombeiros, Malu, Bombom e Zeus em relação ao questionário SNAP-IV. Tecemos, a seguir, algumas considerações.

\section{Discussão}

A presente pesquisa foi construída a partir da escuta de seis estudantes com histórico de fracasso escolar. Embora suas histórias sejam particulares, há uma experiência comum à de muitos estudantes brasileiros: eles foram encaminhados pela escola para um serviço de psicopedagogia, onde aguardavam na fila de espera, a fim de confirmar ou reafirmar, por meio de uma avaliação específica o diagnóstico do TDAH, um transtorno supostamente neurológico que interfere no sucesso escolar se não for tratado. Nessa concepção, as dificuldades vividas no processo de escolarização seriam decorrentes de um problema individual biológico, que demanda uma solução fora da escola e do âmbito pedagógico. Uma solução catalogadora e até mesmo medicamentosa.

No caso dos seis estudantes acompanhados na pesquisa, recuperamos: Quando e onde os comportamentos listados como sintoma de TDAH se manifestam? Em que contexto? Ora, as queixas são produzidas em situações concretas, em um determinado contexto: a desatenção ou a agitação ocorrem na escola. À luz da perspectiva crítica em Psicologia Escolar e Educacional (PATTO, 1990; SOUZA, 2007), entende-se que os comportamentos que motivam a queixa escolar não podem ser descolados da construção do processo de escolarização, que, por sua vez, expressa o complexo processo de enraizamento cultural e apropriação do patrimônio cultural e científico delineado no conteúdo escolar. Em outras palavras, eles expressam características, manifestações e necessidades próprias ao processo de escolarização, à experiência de aprender e conviver em condições específicas.

Nesse sentido, demarcar as dificuldades de escolarização como sendo decorrentes de problemas individuais de aprendizagem ou comportamento anula a experiência concreta, desconsidera o contexto, dando à queixa uma aparência de que ela independe das condições 
sociais e históricas. Se Messi, Goku, Bombeiros, Malu, Bombom e Zeus se comportam assim, é porque são portadores de um suposto transtorno: o TDAH.

No entanto, por meio da análise de suas falas, é possível desnudar que, ao contrário de aleatórios ou desmotivados, para cada suposto sintoma de TDAH, existe uma condição concreta na qual seus comportamentos se dão, a qual compõe a realidade histórico-cultural em que estão inseridos e na qual são constituídos. Muitos falaram da sobrecarga de tarefas na escola, bem como da dificuldade com alguns conteúdos, de onde frisamos a urgência de se pensar em formas de construir o cotidiano escolar na qual as dificuldades sejam vividas como desafio a ser transposto na companhia de educadores e da instituição escolar.

Outro aspecto bastante mencionado é a vontade de conversar e brincar, aumentada pela presença de tantos colegas interessantes. Conversas e brincadeiras não são necessariamente intervenções negativas, mas certamente são vistas como atrapalho quando o formato da aula impõe silêncio, corpo e mente controlados em um trabalho individual e muitas vezes mecânico.

Assim, criticamos o SNAP-IV, na medida em que os 18 comportamentos listados como "sintoma" de um transtorno neurológico são corriqueiros no cotidiano escolar. O olhar patologizante presente no questionário é tanto que, embora ele seja construído a partir de um padrão normativo, as respostas possíveis não incluem que o comportamento naquele quesito possa ser "normal”. Nesse ponto, fazemos coro com o psiquiatra Prof. Dr. Rossano Cabral Lima (2016), ao problematizar os critérios para diagnóstico de TDAH: ora, se uma criança com esse suposto transtorno apresenta os comportamentos listados como sintomas no SNAP-IV, então, uma "criança normal” age de forma contrária. Vejamos:

1. Sempre presta muita atenção a detalhes e nunca comete erros por descuido nos trabalhos da escola ou tarefas;

2. Nunca tem dificuldade de manter a atenção em tarefas ou atividades de lazer;

3. Ouve sempre que falam diretamente com ele;

4. Sempre segue instruções até o fim e termina deveres de escola, tarefas ou obrigações;

5. Organiza tarefas e atividades com facilidade;

6. Se envolve facilmente em tarefas que exigem esforço mental prolongado;

7. Nunca perde coisas necessárias para atividades;

8. Nunca se distrai com estímulos externos;

9. Nunca é esquecido em atividades do dia-a-dia;

10. Não mexe com as mãos ou os pés ou se remexe na cadeira;

11. Não sai do lugar na sala de aula ou em outras situações em que se espera que fique sentado; 
12. Não corre de um lado para outro ou sobe demais nas coisas em situações em que isto é inapropriado;

13. Brinca ou envolve-se em atividades de lazer de forma calma;

14. Nunca está a "mil por hora";

15. Fala pouco;

16. Nunca responde perguntas de forma precipitada antes delas terem sido terminadas;

17. Sempre espera sua vez;

18. Nunca interrompe os outros ou se intromete.

Concordamos com o referido psiquiatra que essa é uma não-criança. Daí que ele inventa a Síndrome da Criança Normal (LIMA, 2016).

Considerando que parte dos supostos sintomas se relacionam ao domínio da atenção, novamente recorremos a Vigotski para ressaltar que a atenção requerida é a voluntária, ou seja, uma função psicológica superior, que, no entanto, é igualada à atenção involuntária. Reiteramos que, "ao fixar na aparente semelhança entre a atenção voluntária e a atenção involuntária, focaliza unicamente o caráter natural, biológico, orgânico, produzindo uma análise superficial da complexa relação entre cultural e biológico no humano", sobretudo porque, "na constituição da atenção voluntária, ou no autodomínio da função psíquica (conversão da atividade interpsíquica em intrapsíquica), o contexto cultural, histórico-social, possui papel fundamental" (RIBEIRO; VIÉGAS, 2016, p. 162).

Diante dessa constatação, frisamos que, diferentemente de reduzir a "falta" ou "déficit" de atenção escolar a um transtorno neurológico, é necessário saber ao que o aluno está (des)atento. Em uma escola árida, na qual conversar e se mexer são sinais de doença neurológica, e que até o brincar deve ser calmo, distrair-se até com uma formiga parece ser forma de sobreviver e respirar. A poesia de Manoel de Barros, O menino do mato (2010), ajuda a nomear: "era preciso desver o mundo para sair daquele lugar imensamente e sem lado", porque "só os absurdos enriquecem a poesia" (p. 9).

A poesia citada encontra ressonância na produção científica de Vigotski (2003), para quem um aspecto importante da atenção é sua relação com o interesse, bem como sua interligação com a distração, vista como "companheira necessária e útil da atenção", já que, "Quando estamos atentos a uma só coisa, inevitavelmente estaremos distraídos com relação a todas as outras." (p. 129). Daí o autor afirmar que a "transformação da distração em atenção tem a ver, a rigor, com o segredo de mudar os ponteiros da atenção de um sentido para o outro, e isso se alcança por meio do método educativo geral de transferir o interesse de um objeto para outro, mediante sua vinculação" (p. 135). 
Tal análise encontra apoio em Eidt, Tuleski e Franco (2014), que afirmam:

A criança escolar ainda não é capaz de regular a sua atenção com firmeza e de dominar seus processos atencionais, submetendo-os à sua vontade, por isso depende muito da mediação do adulto, que direcionará sua atenção para o essencial e a ajudará a estabelecer relações entre os indícios importantes nos conteúdos implicados nas atividades de estudo (p. 89).

A orientação é um fator importante e uma condição para a transformação da atenção natural, que é uma operação involuntária, não mediada, em atenção voluntária, mediada. Vigotski afirma que "os fenômenos da atenção devem ser considerados como certo sistema de reações de orientação [ustanovka], ou seja, das reações preparatórias do organismo que colocam o corpo na postura e no estado necessários e os prepara para a atividade que o espera." (VIGOTSKI, 2003, p. 125-126, grifo do autor e colchete do tradutor). Estas reações dependem da experiência da pessoa.

[...] el desarrollo de la atención del niño, desde los primeros días de su vida, se encuentra en un medio complejo formado por estímulos de un doble género. Por un lado, los objetos y los fenómenos atraen la atención del niño en virtud de sus propiedades intrínsecas; por otro, los correspondientes estímuloscatalizadores, es decir, las palabras orientan la atención del niño. Desde el principio, la atención del niño está orientada. Primero la dirigen los adultos, pero a medida que el niño va dominando el lenguaje, empieza a dominar la misma propiedad de dirigir su atención con respecto a los demás y después en relación consigo mismo ${ }^{6}$ (VIGOTSKI, 1995, p. 232).

Dessa forma, o domínio da atenção está relacionado com a atuação da orientação, e esta, com as atividades sociais. Por outro lado, o domínio da atenção também está relacionado com a eleição/escolha realizada pelo próprio sujeito, ou seja, sua vontade, que é caracterizada pelo domínio dos próprios processos do comportamento. Portanto, a escolha se relaciona com a capacidade de tomar decisões a partir do conhecimento que tem sobre o assunto ou situação. Engloba o autodomínio mediante a atividade mediadora. Assim, entende-se que a vontade e a escolha, como as demais funções psíquicas superiores, estão implicadas no complexo processo do desenvolvimento cultural.

Nesse sentido, não se trata de o aluno ter ou não ter atenção (ou “déficit de atenção"), como se isso fosse determinado biologicamente; mas de reconhecer como escolas, de maneira

\footnotetext{
6 “O desenvolvimento da atenção da criança, desde os primeiros dias de sua vida, está em um ambiente complexo formado por estímulos de duplo gênero. Por um lado, objetos e fenômenos atraem a atenção da criança em virtude de suas propriedades intrínsecas; do outro, os estímulos-catalisadores correspondentes, isto é, as palavras orientam a atenção da criança. Desde o início, a atenção da criança é orientada. Primeiro os adultos a dirigem, mas à medida que a criança domina a língua, ele começa a dominar a mesma propriedade de dirigir sua atenção em relação aos outros e depois em relação a si mesmo" (Tradução nossa).
} 
geral, têm enfrentado desafios para conquistar e provocar a atenção de estudantes, que, notoriamente bem desenvolvida, volta-se para outros aspectos de suas vidas, como jogos, brincadeiras ou a televisão, mas não para a escola. Se a expectativa é de alunos atentos, cumpre analisarmos: as atividades pedagógicas têm ajudado a virar os ponteiros, despertando o interesse dos alunos, elemento indispensável à atenção voluntária?

$\mathrm{O}$ exame dessa pergunta tem indicado o divórcio entre os interesses dos alunos (e professores) e as atividades/conteúdos escolares. De fato, são inúmeras as pesquisas que denunciam o quanto na vida diária escolar encontramos os principais ingredientes da produção de fracasso, sofrimento e encaminhamentos (PATTO, 1990; SOUZA, 2007).

Antes de concluir, importa ressaltar que, ao longo da pesquisa, foi construído um espaço de aprendizado, escuta, observação, diálogo, negociações e acolhimento no qual todos puderam partilhar saberes, experiências e emoções, bem como construir, no próprio processo grupal, uma experiência formativa. Por meio dos encontros, foi notável o envolvimento e interesse de todos com as situações e atividades, negando, portanto, que eles tenham um transtorno neurológico que os torne desatentos ou hiperativos.

É importante ressaltar que existem diferenças entre os dois contextos, a escola e a teia de relações construída na pesquisa de campo, entretanto é possível considerar que as queixas escolares, motivos dos encaminhamentos, são expressões de necessidades inerentes ao processo de escolarização e/ou representam características e manifestações relacionadas à experiência de aprender e conviver com as condições específicas de cada contexto escolar.

As características, manifestações e necessidades de Messi, Goku, Bombeiros, Malu, Bombom e Zeus foram tratadas como expressão das singularidades nas formas de aprender, interagir, viver a infância e adolescência. A queixa e o histórico de fracasso indicam que suas singularidades não foram acolhidas na escola, em função da lógica padronizadora e medicalizante incrustada no cotidiano escolar. Assim, expressões que desafiam os padrões abstratos de normalidade impostos e institucionalizados são traduzidas em termos de dificuldades individuais. Vistas como desvio, elas são enquadradas, submetidas a uma classificação, uma etiqueta que justifique sua exclusão à luz de uma pretensa normalidade. E a necessidade de transformação da escola fica intocada.

Ressaltamos que a lógica da medicalização alicerçada na naturalização do humano tem capturado tanto estudantes quanto profissionais que devem se submeter, se ajustar e se adaptar aos padrões pré-estabelecidos para alcançar o esperado desempenho. No caso dos professores, a lógica medicalizante camufla as condições de trabalho e os desafios da atuação profissional, merecendo destaque: descaso e precarização do espaço público; burocratização das tarefas; 
sobrecarga de trabalho; desvalorização profissional. No caso dos estudantes, as características do processo de escolarização e/ou as dificuldades que enfrentam são, de maneira recorrente, interpretados como dificuldades/distúrbios/transtornos, ou seja, como um problema individual.

Nesse sentido, nos contrapomos à tradução dos comportamentos listados abstratamente no SNAP-IV como sintomas de um suposto transtorno neurobiológico, uma vez que tal diagnóstico, que não se apoia em nenhum exame neurológico, reduz toda a complexidade da vida social a uma gramática medicalizante. Tais comportamentos, ao contrário, são manifestações e expressões de crianças e adolescentes que vivem, aprendem, sentem, pensam, criam, convivem... em contextos histórico-culturais concretos. Desconsiderar isso decorre de uma leitura biologizada e naturalizada das experiências humanas, ocultando, camuflando e/ou negligenciando as condições nas quais elas se constituem e se produzem.

Na contramão, apostamos que é possível que a escola se constitua em espaço de escuta, acolhimento, confronto, aprendizado e diálogo, superando a lógica medicalizante. Muito vem sendo produzido nessa rota, com destaque para as Recomendações de práticas não medicalizantes para profissionais e serviços de saúde e educação, publicadas pelo Fórum sobre Medicalização da Educação e da Sociedade (2012). No referido documento, o Fórum ressalta que tais recomendações não se caracterizam como um manual fechado de diagnósticos e condutas. Posto isso, sinaliza, como ponto de partida, que a superação do olhar medicalizante implica em não focalizar apenas o que falta ao aluno (como atenção ou disciplina), mas buscar suas potencialidades, o que demanda conectar-se com o sujeito singular, e não operar com a ultrageneralização que sustenta os manuais normativos. "Não seria interessante mudar a lógica da culpa para a busca de possibilidades de compreensão dos envolvidos no processo ensinoaprendizagem e ampliar as intervenções e ações na escola?" (p. 43).

Segundo o Fórum (2012), as escolas têm terreno propício à consolidação de práticas não-medicalizantes, na medida em que é comum que educadores reconheçam que o número de alunos em sala de aula, a arquitetura da escola, as políticas educacionais, os materiais pedagógicos, o salário e as condições de trabalho afetam a aprendizagem e o comportamento dos alunos, o que denuncia que eles não são o foco do problema. Assim, em síntese, se a escolarização é um fenômeno complexo, a recomendação é que se busquem estratégias que reconheçam essa complexidade: implicar a escola como um todo na construção de projetos pedagógicos; discutir e refletir coletivamente sobre iniciativas e estratégias bem sucedidas; planejar estratégias grupais; articular os interesses de alunos e o de professores no planejamento das atividades pedagógicas; aprender e ensinar a conviver com a diferença. 
Sabemos que a transformação da escola não depende da vontade individual de alunos e professores (PATTO, 1990; SOUZA, 2007; SOUZA, 2006). Sabemos, contudo, ser fundamental a implicação de todos para que possamos desver a medicalização da educação, e então juntos sairmos desse lugar tão imensamente e sem lado.

\section{REFERÊNCIAS}

ABDA. Associação Brasileira do Déficit de Atenção. Diagnóstico em crianças: SNAP-IV, 2017. Disponível em <https://tdah.org.br/diagnostico-criancas/>. Acesso em: 25 nov. 2019.

BARROS, Manoel de. Menino do mato. Lisboa: Editora LeYa, 2010.

BRZOZOWSKI, Fabiola Stolf; CAPONI, Sandra. Determinismo biológico e as neurociências no caso do transtorno de déficit de atenção com hiperatividade. Physis: Revista de Saúde Coletiva, Rio de Janeiro, IMS-UERJ, v. 22, n. 3, p. 941-961, 2012. Disponível em <http://www.scielo.br/scielo.php?script=sci_arttext\&pid=S0103$73312012000300006 \& \operatorname{lng}=\mathrm{en} \& \mathrm{nrm}=\mathrm{iso}>$. Acesso em: 25 nov. 2019.

CHECCHIA, Ana Karina Amorim. O que jovens alunos de classes populares têm a dizer sobre a experiência escolar na adolescência. 234 f. Dissertação (Mestrado em Psicologia Escolar e do Desenvolvimento Humano). Programa de Pós-Graduação em Psicologia, Universidade de São Paulo, São Paulo, 2006. Orientadora: Profa. Dra. Marilene Proença Rebello de Souza.

DSM-IV-TR. Manual diagnóstico e estatístico de transtornos mentais. Tradução Cláudia Dornelles. Porto Alegre: Artmed, 2003.

DSM-5. Manual de diagnóstico e estatística das perturbações mentais. Tradução Médicos do Centro Hospitalar de Lisboa. Lisboa: Climepsi Editores, 2014.

EIDT, Nádia Mara; TULESKI, Silvana Calvo; FRANCO, Adriana de Fátima. Atenção não nasce pronta: o desenvolvimento da atenção voluntária como alternativa à medicalização. Nuances: estudos sobre Educação, Presidente Prudente-SP, FTC/UNESP, v. 25, n.1, p.78-96, jan./abr. 2014. Disponível em:

<http://revista.fct.unesp.br/index.php/Nuances/article/viewFile/2759/2519>. Acesso em: 25 nov. 2019.

FÓRUM SOBRE MEDICALIZAÇÃO DA EDUCAÇÃO E DA SOCIEDADE. GRUPO DE TRABALHO EDUCAÇÃO \& SAÚDE. Recomendações de práticas não medicalizantes para profissionais e serviços de saúde e educação. São Paulo, 2012. Disponível em <http://medicalizacao.com.br/wp-content/uploads/2012/11/RECOMENDACOES.pdf>. Acesso em: 25 nov. 2019.

FÓRUM SOBRE A MEDICALIZAÇÃO DA EDUCAÇÃO E DA SOCIEDADE. Carta do IV Seminário Internacional A Educação Medicalizada: desver o mundo, perturbar os sentidos. In: SEMINÁRIO SOBRE A EDUCAÇÃO MEDICALIZADA, 4, 2015a, Salvador-BA. Anais... 
Fórum Sobre Medicalização da Educação e da Sociedade, 2016, v.1, n.1, s/p. Disponível em: <http://anais.medicalizacao.org.br/index.php/educacaomedicalizada/article/view/4/6>. Acesso em 25 nov. 2019.

\section{FÓRUM SOBRE MEDICALIZAÇÃO DA EDUCAÇÃO E DA SOCIEDADE. Nota} Técnica: O consumo de psicofármacos no Brasil - dados do Sistema Nacional de Gerenciamento de Produtos Controlados (2007-2014). São Paulo, 2015b. Disponível em: <http://medicalizacao.org.br/nota-tecnica/>. Acesso em: 25 nov. 2019.

FÓRUM SOBRE A MEDICALIZAÇÃO DA EDUCAÇÃO E DA SOCIEDADE. Manifesto Desmedicalizante e Interseccional: “existirmos, a que será que se destina?". SEMINÁRIO SOBRE A EDUCAÇÃO MEDICALIZADA, 5, 2018, Salvador-BA. Anais... Fórum Sobre Medicalização da Educação e da Sociedade, 2019, v.1, n.1, p. 12-20. Disponível em: <http://anais.medicalizacao.org.br/index.php/educacaomedicalizada/article/view/235/205>. Acesso em 25 nov. 2019.

LIMA, Rossano Cabral. Somos todos desatentos: o TDA/H e a construção de bioidentidades. Rio de Janeiro: Relume Dumará, 2005.

LIMA, Rossano Cabral. Psiquiatria infantil, medicalização e a Síndrome da Criança Normal. In: Comissão de Psicologia e Educação do CRP-RJ (Org.). Conversações em Psicologia e Educação. Rio de Janeiro: Conselho Regional de Psicologia $5^{a}$ Região, 2016, pp. 61-72. Disponível em: <http://www.crprj.org.br/site/wpcontent/uploads/2016/10/livro_psicologia_educacao.pdf >. Acesso em: 25 nov. 2019.

MOYSÉS, Maria Aparecida Affonso; COLLARES, Cecília Azevedo Lima. Dislexia e TDAH: uma análise a partir da ciência médica. In: CONSELHO REGIONAL DE PSICOLOGIA DE SÃO PAULO; GRUPO INTERINSTITUCIONAL QUEIXA ESCOLAR (Org.). Medicalização de crianças e adolescentes: conflitos silenciados pela redução de questões sociais a doenças de indivíduos. São Paulo: Casa do Psicólogo, 2010, p. 71-110.

MOYSÉS, Maria Aparecida Affonso; COLLARES, Cecília Azevedo Lima. Medicalização do comportamento e da aprendizagem: a nova face do obscurantismo. In: VIÉGAS, Lygia de Sousa; RIBEIRO, Maria Izabel Souza; OLIVEIRA, Elaine Cristina; ALVES, Liliane Alves da Luz. Medicalização da Educação e da Sociedade: ciência ou mito?. Salvador: EDUFBA, 2014, p. 19-43.

NOVARTIS. Ritalina®: Cloridrato de metilfenidato. São Paulo: NOVARTIS (Bula de Remédio), 2010.

OLIVEIRA, Elaine Cristina de; HARAYAMA, Rui Massato; VIÉGAS, Lygia de Sousa. Drogas e medicalização na escola: reflexões sobre um debate necessário. Revista Teias, Rio de Janeiro, PROPED/UERJ, v. 17, n. 45, p. 99-118, abr./jun. 2016. Disponível em <https://www.e-publicacoes.uerj.br/index.php/revistateias/article/view/24598/17578>. Acesso em: 25 nov. 2019.

PATTO, Maria Helena Souza. A Produção do Fracasso Escolar: histórias de submissão e rebeldia. São Paulo: T. A. Queiroz, 1990. 
PRESTES, Zoia Ribeiro. Quando não é quase a mesma coisa: análise de traduções de Lev Semionovitch Vigotski no Brasil repercussões no campo educacional. 295 f. Tese. (Doutorado em Educação). Faculdade de Educação, Universidade de Brasília, Brasília, 2010. Orientadora: Profa. Dra. Elizabeth Tunes.

RIBEIRO, Maria Izabel Souza. A medicalização na escola: uma crítica ao diagnóstico do suposto Transtorno de Déficit de Atenção e Hiperatividade (TDAH). 267f. Tese (Doutorado em Educação). Faculdade de Educação, Universidade Federal da Bahia (UFBA), Salvador, 2015. Orientadora: Profa. Dr ${ }^{a}$ Lygia de Sousa Viégas.

RIBEIRO, Maria Izabel Souza; VIÉGAS, Lygia de Sousa. A abordagem histórico-cultural na contramão da medicalização: uma crítica ao suposto TDAH. Germinal: Marxismo e Educação em Debate, Salvador, v. 8, n. 1, p. 157-166, jun. 2016. Disponível em: < https://portalseer.ufba.br/index.php/revistagerminal/article/view/14867/11684>. Acesso em 25 nov. 2019.

SOUZA, Beatriz de Paula. Orientação à queixa escolar. São Paulo: Casa do Psicólogo, 2007.

SOUZA, Denise Trento Rebello de. Formação continuada de professores e fracasso escolar: problematizando o argumento da incompetência. Educação e Pesquisa, São Paulo, Faculdade de Educação da Universidade de São Paulo, v. 32, n. 3, p. 477-492, Dez. 2006. Disponível em: <http://www.scielo.br/scielo.php?script=sci_arttext\&pid=S1517-

97022006000300004\&lng=en\&nrm=iso >. Acesso em: 25 nov. 2019.

SNGPC - Sistema Nacional de Gerenciamento de Produtos Controlados. Prescrição e consumo de metilfenidato no Brasil: identificando riscos para o monitoramento e controle sanitário. Boletim de Farmacoepidemiologia do SNGPC, Brasília, ANVISA, Ano 2, n. 2, p. 1-14, jul./dez. de 2012. Disponível em:

<http://www.anvisa.gov.br/sngpc/boletins/2012/boletim_sngpc_2_2012_corrigido_2.pdf>. Acesso em: 12 ago 2019.

VIGOTSKI, Lev Semyonovich. Obras escogidas: Tomo III - Problemas del desarrollo de la psique. Traducción de Lydia Kuper. Revisión e adaptación Napoleon Jesus Vidarte Vargas y Irina Filanova. Madri: Visor, 1995. 383 p.

VIGOTSKI, Lev Semyonovich. Obras Escogidas: Tomo V - Fundamentos de Defectologia. Traducción de Julio Guillermo Blank. Revisión e adaptación Napoleon Jesus Vidarte Vargas y Irina Filanova Madri: Visor, 1997. 391 p.

VIGOTSKI, Lev Semyonovich. Psicologia pedagógica. Tradução de Claudia Schilling. Edição comentada por Guilhermo Blanck. Porto Alegre: Artmed, 2003. 


\section{SOBRE AS AUTORAS:}

\section{Maria Izabel Souza Ribeiro}

Doutora em Educação, FACED-UFBA; Docente da Faculdade de Educação da UFBA, Salvador, Bahia, Brasil; Membro do Grupo de Pesquisa EPIS: Educação, Política, Indivíduo e Sociedade: leituras a partir da Pedagogia, da Psicologia e da Filosofia. Correio eletrônico: misribeiro1@gmail.com

iD http://orcid.org/0000-0003-4617-7912

\section{Lygia de Sousa Viégas}

Doutora em Psicologia Escolar e do Desenvolvimento Humano, IPUSP; Docente da Faculdade de Educação da UFBA, Salvador, Bahia, Brasil; Professora credenciada no Programa de PósGraduação em Educação da FACED-UFBA; Membro do Grupo de Pesquisa EPIS: Educação, Política, Indivíduo e Sociedade: leituras a partir da Pedagogia, da Psicologia e da Filosofia. Correio eletrônico: lyosviegas@gmail.com

(iD http://orcid.org/0000-0002-2353-0384

\section{Elaine Cristina de Oliveira}

Doutora em Linguística, UNICAMP; Docente do Departamento de Fonoaudiologia da UFBA, Salvador, Bahia, Brasil; Professora credenciada no Programa de Pós-Graduação em Educação da FACED-UFBA; Membro do Grupo de Pesquisa EPIS: Educação, Política, Indivíduo e Sociedade: leituras a partir da Pedagogia, da Psicologia e da Filosofia. Correio eletrônico: elaineoliveira1009@gmail.com

(iD) http://orcid.org/0000-0001-8393-4025

Recebido em: 11 de outubro de 2019 